\title{
A Survey on the Status of Hepatitis E Virus Infection Among Slaughterhouse Workers in South Korea
}

\author{
Byung-Seok Kim', Hyun-Sul Lim', Kwan Lee', Young-Sun Min', Young-Sil Yoon², Hye-Sook Jeong² \\ ${ }^{1}$ Department of Preventive Medicine, Dongguk University College of Medicine, Gyeongju; '2Division of Vaccine Research, Korea Centers for Disease \\ Control and Prevention, Cheongju, Korea
}

Objectives: The seroprevalence of hepatitis E virus (HEV) among high-risk groups overseas is high, but studies in these groups are rare in South Korea. We conducted the present study from April to November 2012 to obtain data on the seroprevalence and associated risk factors for HEV among slaughterhouse workers in South Korea.

Methods: Slaughterhouse workers from 80 workplaces nationwide were surveyed in South Korea in 2012. The subjects comprised 1848 cases: 1434 slaughter workers and 414 residual products handlers. By visiting 80 slaughterhouses, which were mixed with 75 of which also performed residual products handling, we conducted a questionnaire survey for risk factors and obtained blood samples in order to determine the seropositivity and seroprevalence of HEV. Anti-HEV IgG and IgM were measured using HEV IgG and IgM enzyme-linked immunospecific assay kits and HEV antigen was measured by reverse transcription polymerase chain reaction (RT-PCR).

Results: The seropositivity of anti-HEV IgG was $33.5 \%$ (slaughter workers $32.8 \%$ and residual products handlers $36.2 \%$ ), and among the seropositive individuals the seroprevalence of anti-HEV IgM was $0.5 \%$ (slaughter workers $0.5 \%$, residual products handlers $0.7 \%$ ). The response rate of HEV-antigen as measured by RT-PCR was $0.2 \%$. Risk factors significantly related to anti-HEV IgG seropositivity were age, sex, and working duration (slaughter workers only).

Conclusions: There were significant risk factors (sex, age, and working duration) for HEV identified in our study. All three positive cases for HEV-antigen by RT-PCR were related to pig slaughter but without statistical significance. To prevent HEV, an educational program and working guidelines may be needed for high risk groups.

Key words: Hepatitis E, Slaughterhouse, Zoonoses, Seroprevalence, Risk factors

\section{INTRODUCTION}

The prevention and control of zoonoses are of increasing concern among health authorities because of the rise and

Received: November 6, 2014 Accepted: December 24, 2014

Corresponding author: Hyun-Sul Lim, MD, PhD

123 Dongdae-ro, Gyeongju 780-714, Korea

Tel: +82-54-770-2401, Fax: +82-54-770-2438

E-mail:wisewine@dongguk.ac.kr

This is an Open Access article distributed under the terms of the Creative Commons Attribution Non-Commercial License (http://creativecommons.org/licenses/bync/3.0/) which permits unrestricted non-commercial use, distribution, and reproduction in any medium, provided the original work is properly cited. spread of new zoonotic disease. In a systematic review of 1415 pathogens known to infect humans, $61 \%$ were classified as zoonotic [1]. In South Korea, the study of zoonoses has progressed as concerns have increased. Previous studies on zoonoses have investigated brucellosis infections, $Q$ fever, enterohemorrhagic Escherichia coli infections, toxoplasmosis, and Lyme disease in livestock breeders, veterinarians, artificial inseminators, and slaughterhouse workers and inspectors [2-6].

Hepatitis E virus (HEV) causes around 20 million infections per year, resulting in around 3 million cases of acute illness. As of 2010, the HEV virus was responsible for 60000 deaths annually [7]. In 1996, anti-HEV IgG was detected in $9.5 \%$ of healthy adults in South Korea [8]. The seropositivity of anti-HEV IgG was 
$11.9 \%$ among the Korean population, and among them the seropositivity was $15.0 \%$ in those aged 40 to 60 years old and living in rural areas [9]. In another study in 2001, the seropositivity of anti-HEV IgG was $23.1 \%$, and among them the seropositivity was $42.3 \%$ in those aged 60 years and above [10]. The nationwide seropositivity of anti-HEV IgG was found to be $5.9 \%$ in the Korean population in 2007 to 2009 [11].

The morbidity rate of zoonotic infections is higher in workers who come into frequent contact with animals, and is also correlated with the frequency and type of animal contact, factors which are often based on occupational requirements. In industrialized countries, domestic animals, including swine and cattle, are an important reservoir for HEV [12]. During surveillance, high-risk groups for zoonotic infections include pig farmers, veterinarians, and slaughterhouse workers, who show high morbidity compared to control groups [13]. According to a recent study, slaughterhouse workers have a 1.5 to 3.5 times higher risk for morbidity than other workers who had not had any occupational contact with animals [14]. Therefore the seroprevalence, transmission route, and risk factors for HEV in high-risk groups in South Korea need to be identified. However, the status of or risk factors for zoonotic HEV infection have not been sufficiently investigated in South Korea. This study was therefore conducted to report the status and risk factors associated with zoonotic HEV infection among slaughterhouse workers.

\section{METHODS}

\section{Study Subjects}

In 2012, 85 slaughterhouses in South Korea were registered with the Ministry for Food, Agriculture, Forestry and Fisheries. Eighty of these were selected (two had ceased work and another three refused to participate). Slaughterhouses were distributed all over the country, located in Chungcheongbuk-do (13 sites); Gyeonggi-do (11); Gyeongsangbuk-do (10); Jeollanam-do (10); Chungcheongnam-do (8); Gyeongsangnam-do and Jeollabuk-do (7); Gangwon-do (5); Kwangju-si, Ulsan-si, and Inchen-si (2); Daegu-si, Daejeon-si, and Jeju-do (1). There were 2145 slaughterhouse workers belonging to the 80 slaughterhouses, which were mixed with 75 of which also performed residual product handling (1699 slaughter workers and 446 residual product handlers), and the workers were registered with the Livestock Health Control Association, Korea Centers for Disease Control and Prevention (K-CDC), and Statistics Korea. Of these, 1848 (86.2\%) workers (1434 slaughter workers and 414 residual product handlers) were surveyed in 2012.

\section{Development of Questionnaire}

The structure of the slaughterhouse, slaughtering process, working characteristics of workers and risk factors for HEV infection were identified through a literature review [15-17]. From this review, separate questionnaires were developed for slaughterhouse workers and residual product handlers. These included contents such as the general characteristics of each worker, as well as any work-related and lifestyle-related risk factors, and whether or not the workers wear personal protective equipment (PPE). In addition, we used a questionnaire modified from a previous study [5].

The statements regarding risk factors were "Always disinfecting working tools and body surfaces after work" and "Being in contact with blood and secretions of livestock around the mouth and body (more than once a week)". Another set of statements pertained to lifestyle, for example, "eating raw beef, pork, cattle or pig by-products, or raw milk", "donating blood", "handling livestock with skin wounds" and "breeding cattle, pigs, goats, dogs or cats". The statement regarding PPE was "Always wearing protective eyeglasses, protective masks, long protective gloves, protective aprons, protective boots, and disposable protective clothes". These statements were answered "yes" or "no".

\section{Survey}

Our study team consisted of four or five persons, including one doctor, one medical technologist, and two or three trained interviewers. The study was conducted from June 11 to June 22 in 2012. The questionnaire and official documents for participation in the study were sent to each slaughterhouse, and the questionnaire was completed prior to the study team's visit. Incomplete questionnaires were completed by verifying questionnaires and interviewing workers individually.

\section{Serological Testing}

After sampling blood ( $10 \mathrm{~mL}$ ), serum was separated by centrifugation. The serum was given a serial number, stored in a sealed icebox with icepacks, and transferred to the K-CDC for serologic tests. Wantai HEV-lgG and HEV-lgM enzyme-linked immunosorbent assay (ELISA) kits (Wantai Biological Pharmacy Enterprise Co., Beijing, China) were used for qualitative determination of IgG- and IgM-class antibodies to HEV in human serum. The results were calculated by relating each specimen absorbance $(\mathrm{A})$ value to the cut-off value (CO) of the plate. The diagnostic criteria were as follows: 1$)$ Negative results $(A / C O<1)$ : 
samples giving an A value less than the $\mathrm{CO}$ were negative, indicating that no HEV IgG- or IgM-class antibodies had been detected by the kit, and that therefore there were no serological indications for current infection with HEV. 2) Positive results (A/ $C O \geq 1)$ : samples giving an $A$ value equal to or greater than the $\mathrm{CO}$ were considered initially reactive, indicating that lgG- and IgM-class antibodies to HEV had probably been detected by the kit. Repeatedly reactive samples could be considered positive for IgG- and IgM-class antibodies to HEV and that therefore the patient was probably infected with $\mathrm{HEV}$. 3 ) Borderline: $(\mathrm{A} / \mathrm{CO}=0.9$ 1.1): samples with an $A$ value to $C O$ between 0.9 and 1.1 were considered borderline and retesting of these specimens in duplicates was required to confirm the initial results. After measuring the antibody titers of HEV, an HEV-lgM test was conducted on samples that were positive for the HEV-IgG test. HEV RNA was detected using reverse transcriptase polymerase chain reaction (RT-PCR) after HEV-IgM titer was confirmed. Seropositivity was defined as a positive result in the HEV-IgG test. Seroprevalence was defined as a positive result in the HEV-IgM test. This study was approved by the institutional review board of Dongguk University Gyeongju Hospital (no. 12-033). Participants made their informed consent prior to enrollment in the study.

\section{Statistical Analysis}

PASW Statistics version 18.0 (SPSS Inc., Chicago, IL, USA) was used for statistical analyses. HEV-IgG seropositivity by sex, occupational group, risk factors, and wearing PPE was analyzed using chi-square and Fisher's exact tests, and seropositivity by age group and working duration was analyzed using the chisquare for trend test. Using significant factors associated with HEV IgG positivity, we performed binomial logistic regression. For all tests, $p<0.05$ was considered statistically significant.

\section{RESULTS}

\section{Hepatitis E Virus Seropositivity and Seroprevalence}

The seropositivity for anti-HEV IgG in slaughter workers and residual products handlers, respectively, was $32.8 \%$, and $36.2 \%$. The seroprevalence for anti-HEV IgM in slaughter workers and residual products handlers was $0.5 \%$, and $0.7 \%$, respectively. The RT-PCR-reactive rate in slaughter workers and residual products handlers, respectively, was $0.2 \%$, and $0.0 \%$ (Table 1 ).

The seropositivity in men (34.0\%) was significantly higher $(p<0.001)$ than that of women $(15.4 \%)$ among slaughter workers. The seropositivity significantly increased with age ( $p<$ 0.001 ), and seropositivity was highest in subjects aged 60 years and above (60.6\%). The seropositivity also significantly increased with working duration $(p<0.001)$ (Table 2$)$. The seropositivity in men $(42.6 \%)$ was significantly higher $(p=0.029)$ than that of women $(32.1 \%)$ among residual product handlers. The seropositivity increased significantly with age $(p<0.001)$; seropositivity in the 40 to 49,50 to 59 , and 60 years and over age groups was $23.3 \%, 36.3 \%$, and $51.9 \%$ respectively. There were no significant differences between working duration and seropositivity (Table 2).

Anti-HEV IgM was detected in seven subjects (0.5\%). Of these, six were men (85.7\%). Five of the slaughterhouse workers who tested positive for anti-HEV IgM were in the 50 to 59 year age group (71.4\%) (Table 2). Among residual product handlers, the seroprevalence for anti-HEV IgM was $0.7 \%$. All three positive cases were male. Seroprevalence in the under 40,40 to 49 , and 50 to 59 year age groups was $33.3 \%, 33.3 \%$, and $33.3 \%$ respectively (Table 2).

\section{Characteristics of Reverse Transcriptase Poly- merase Chain Reaction Positivity}

An RT-PCR analysis was completed on ten positive specimens for anti-HEV IgM. The HEV antigen was detected in three subjects. The detection rate of HEV RNA using RT-PCR was $0.2 \%$. All three subjects who were positive for HEV RNA were male slaughterhouse workers. One of these was under 40 years old, while the other two subjects were in the 50 to 59 year age group.

Table 1. Positive test results for anti-HEV IgG and IgM by ELISA and HEV-antigen by RT-PCR among slaughterhouse workers and residual products handlers

\begin{tabular}{|c|c|c|c|c|c|c|}
\hline \multirow{2}{*}{ Tests } & \multicolumn{2}{|c|}{ Slaughter workers $(n=1434)$} & \multicolumn{2}{|c|}{ Residual products handlers $(n=414)$} & \multicolumn{2}{|c|}{ Total $(\mathrm{n}=1848)$} \\
\hline & No. of positive & $\%$ & No. of positive & $\%$ & No. of positive & $\%$ \\
\hline Anti-HEV IgG (seropositivity) & 470 & 32.8 & 150 & 36.2 & 620 & 33.5 \\
\hline Anti-HEV IgM (seroprevalence) & 7 & 0.5 & 3 & 0.7 & 10 & 0.5 \\
\hline HEV-antigen by RT-PCR & 3 & 0.2 & 0 & 0.0 & 3 & 0.2 \\
\hline
\end{tabular}

HEV, hepatitis E virus; ELISA, enzyme-linked immunosorbent assay; RT-PCR, reverse transcriptase polymerase chain reaction. 
Table 2. Positive test results for anti-HEV IgG and IgM according to sex, age, and working duration among slaughterhouse workers and residual products handlers

\begin{tabular}{|c|c|c|c|c|c|c|c|c|}
\hline \multirow{2}{*}{ Characteristics } & \multicolumn{4}{|c|}{ Slaughter workers $(n=1434)$} & \multicolumn{4}{|c|}{ Residual products handlers $(n=414)$} \\
\hline & No. of examinees & No. of positive & $\%$ & $p$-value & No. of examinees & No. of positive & $\%$ & $p$-value \\
\hline \multicolumn{9}{|l|}{ Anti-HEV IgG } \\
\hline \multicolumn{9}{|l|}{ Sex } \\
\hline Male & 1343 & 456 & 34.0 & $<0.001^{1}$ & 205 & 83 & 40.5 & $0.07^{1}$ \\
\hline Female & 91 & 14 & 15.4 & & 209 & 67 & 32.1 & \\
\hline \multicolumn{9}{|l|}{ Age (y) } \\
\hline$<40$ & 257 & 19 & 7.4 & $<0.001^{2}$ & 40 & 7 & 17.5 & $<0.001^{2}$ \\
\hline $40-49$ & 371 & 69 & 18.6 & & 73 & 17 & 23.3 & \\
\hline $50-59$ & 585 & 248 & 42.4 & & 193 & 70 & 36.3 & \\
\hline$\geq 60$ & 221 & 134 & 60.6 & & 108 & 56 & 51.9 & \\
\hline \multicolumn{9}{|c|}{ Working duration (y) } \\
\hline$<10$ & 683 & 166 & 24.3 & $<0.001^{2}$ & 247 & 84 & 34.0 & $0.20^{2}$ \\
\hline $10-19$ & 403 & 131 & 32.5 & $(n=1393)$ & 111 & 41 & 36.9 & $(n=407)$ \\
\hline $20-29$ & 222 & 106 & 47.7 & & 38 & 18 & 47.4 & \\
\hline$\geq 30$ & 85 & 55 & 64.7 & & 11 & 4 & 36.4 & \\
\hline \multicolumn{9}{|l|}{ Anti-HEV IgM } \\
\hline \multicolumn{9}{|l|}{ Sex } \\
\hline Male & 1343 & 6 & 0.4 & $0.37^{3}$ & 205 & 3 & 1.5 & $0.12^{3}$ \\
\hline Female & 91 & 1 & 1.1 & & 209 & 0 & 0.0 & \\
\hline \multicolumn{9}{|l|}{ Age (y) } \\
\hline$<40$ & 257 & 1 & 0.4 & $0.37^{2}$ & 40 & 1 & 2.5 & $0.09^{2}$ \\
\hline $40-49$ & 371 & 0 & 0.0 & & 73 & 1 & 1.4 & \\
\hline $50-59$ & 585 & 5 & 0.9 & & 193 & 1 & 0.5 & \\
\hline$\geq 60$ & 221 & 1 & 0.5 & & 108 & 0 & 0.0 & \\
\hline \multicolumn{9}{|c|}{ Working duration (y) } \\
\hline$<10$ & 683 & 3 & 0.4 & $0.31^{2}$ & 247 & 3 & 1.2 & $0.22^{2}$ \\
\hline 10-19 & 403 & 0 & 0.0 & $(n=1393)$ & 111 & 0 & 0.0 & $(n=407)$ \\
\hline $20-29$ & 222 & 4 & 1.8 & & 38 & 0 & 0.0 & \\
\hline$\geq 30$ & 85 & 0 & 0.0 & & 11 & 0 & 0.0 & \\
\hline
\end{tabular}

HEV, hepatitis E virus.

${ }^{1}$ Tested by chi squared test.

${ }^{2}$ Tested by chi squared for trend test.

${ }^{3}$ Tested by Fisher's exact test.

\section{Risk Factors for Hepatitis E Virus Seropositivity}

Seropositivity in slaughter workers was found to be associated with work-related factors, including wearing long protective gloves $(p=0.008)$, protective aprons $(p=0.001)$, boots $(p=0.049)$, and disposable protective clothes $(p=0.003)$. On the other hand, residual product handlers were more likely to become infected with zoonotic HEV through contact with body secretions ( $p=0.009$ ) (Table 3). Moreover, seropositive slaughter workers were also likely to have consumed raw beef $(p=0.018)$ and raw pork $(p=0.011)$. Residual product handlers had no additional factors contributing to work-related risk factors (Table 4).

\section{Multivariate Analysis with Risk Factors}

Table 5 shows the results of the multivariate logistic regression that identified factors associated with seropositivity. The significant factors associated with seropositivity were male sex old age, wearing protective aprons and eating raw beef in slaughter workers. Among residual products handlers, the statistically significant factors associated with seropositivity were male sex and old age. 


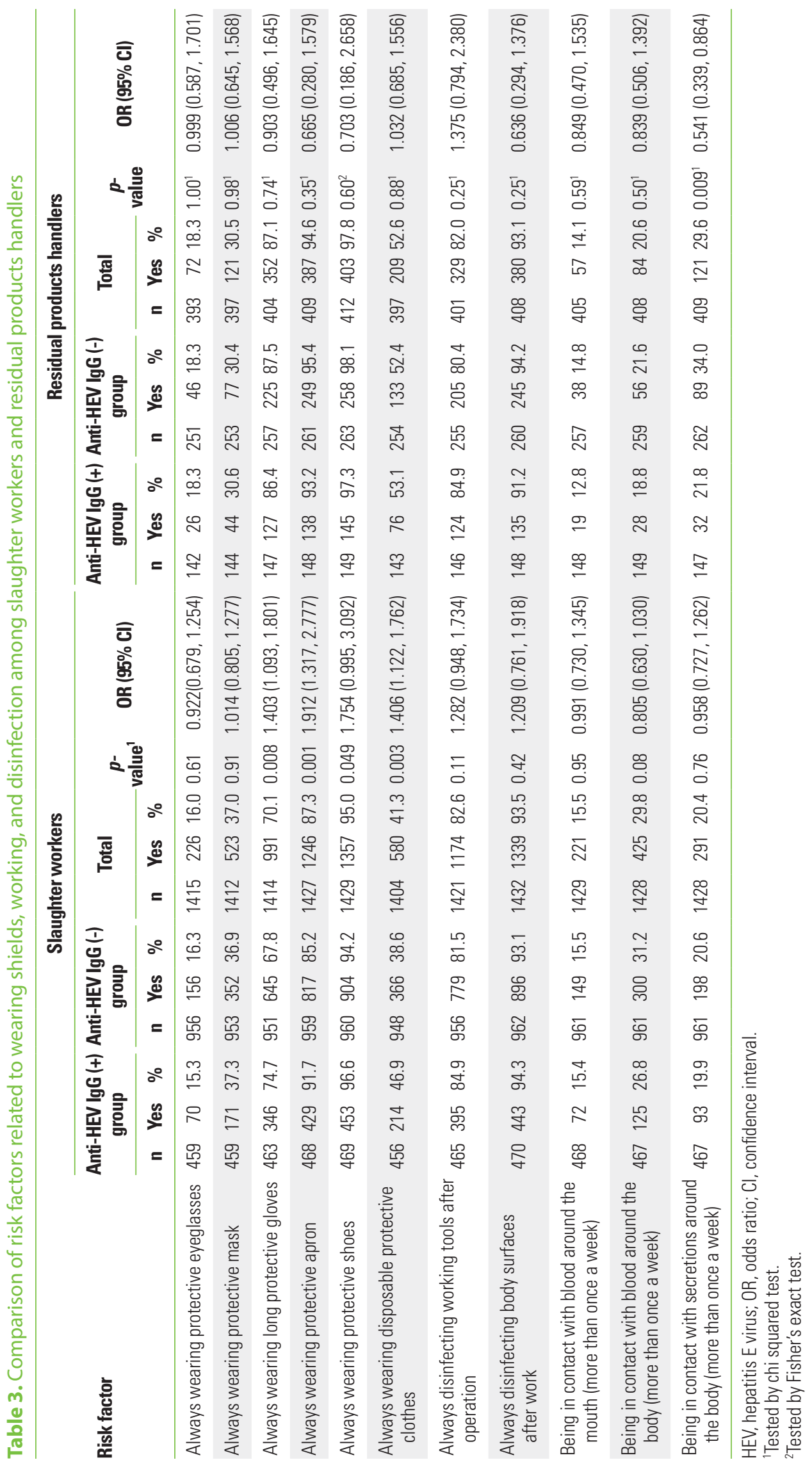




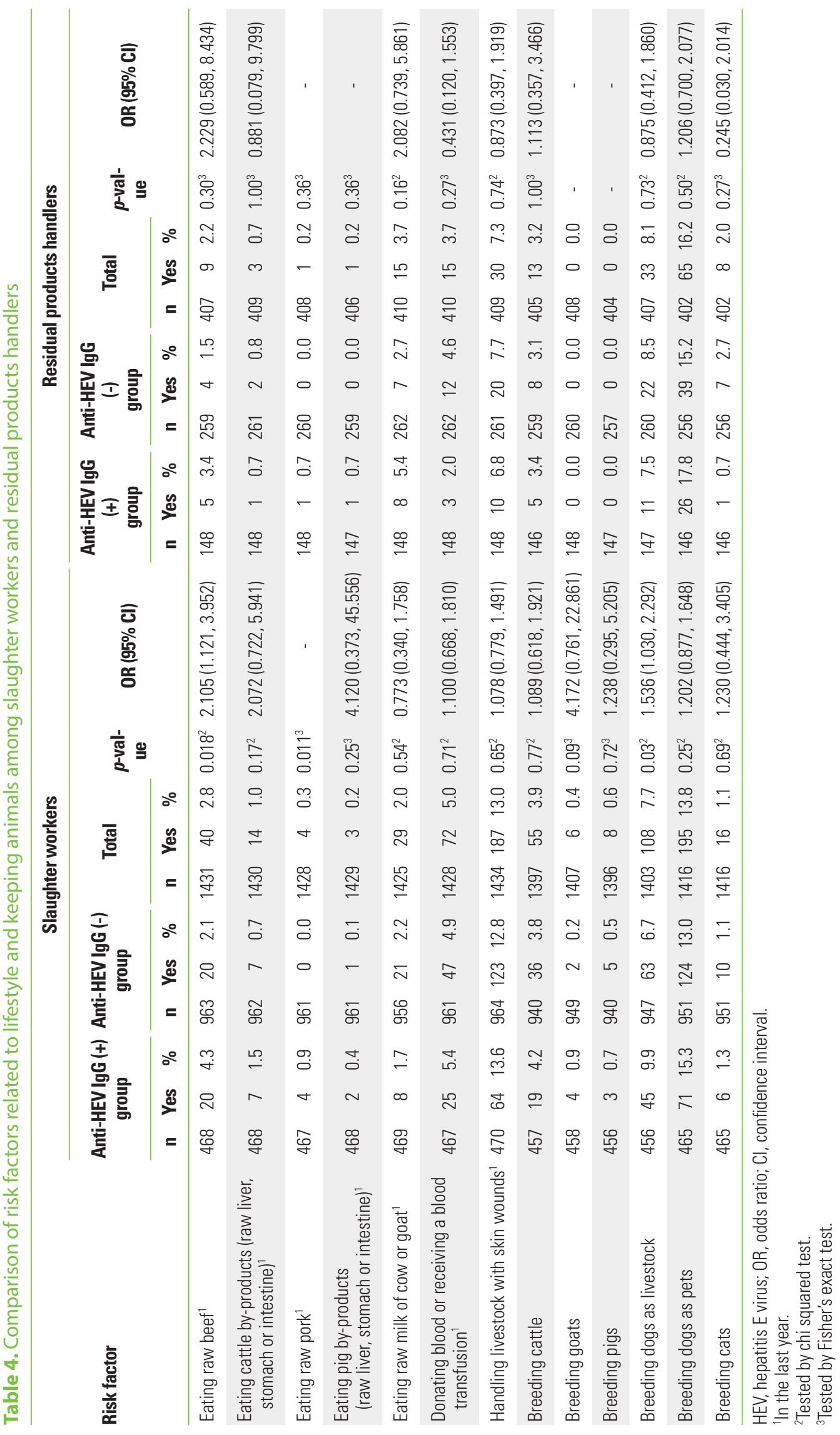


Table 5. Risk factors associated with hepatitis E virus infection in the multivariate analysis

\begin{tabular}{|c|c|c|c|}
\hline \multirow{2}{*}{ Factor } & \multirow{2}{*}{ OR } & \multicolumn{2}{|c|}{ OR (95\% CI) } \\
\hline & & Lower & Upper \\
\hline \multicolumn{4}{|c|}{ Slaughter workers } \\
\hline \multicolumn{4}{|l|}{ Sex } \\
\hline Male & 4.195 & 2.154 & 8.169 \\
\hline Female & Reference & & \\
\hline \multicolumn{4}{|l|}{ Age (y) } \\
\hline$<40$ & Reference & & \\
\hline $40-49$ & 2.913 & 1.651 & 5.141 \\
\hline $50-59$ & 9.882 & 5.831 & 16.747 \\
\hline$\geq 60$ & 20.697 & 11.657 & 36.747 \\
\hline \multicolumn{4}{|c|}{ Wearing protective apron } \\
\hline Yes & 2.000 & 1.304 & 3.068 \\
\hline No & Reference & & \\
\hline \multicolumn{4}{|c|}{ Eating raw beef ${ }^{1}$} \\
\hline Yes & 2.466 & 1.222 & 4.976 \\
\hline No & Reference & & \\
\hline \multicolumn{4}{|c|}{ Residual products handlers } \\
\hline \multicolumn{4}{|l|}{ Sex } \\
\hline Male & 1.855 & 1.188 & 2.896 \\
\hline Female & Reference & & \\
\hline \multicolumn{4}{|l|}{ Age (y) } \\
\hline$<40$ & Reference & & \\
\hline $40-49$ & 2.310 & 0.768 & 6.946 \\
\hline $50-59$ & 5.107 & 1.837 & 14.199 \\
\hline$\geq 60$ & 9.400 & 3.311 & 26.691 \\
\hline
\end{tabular}

$\mathrm{OR}$, odds ratio; $\mathrm{Cl}$, confidence interval.

${ }^{1}$ In the last year.

\section{DISCUSSION}

In this study, we examined HEV seropositivity and seroprevalence in slaughterhouse workers in South Korea. Compared to previous studies [9-11,14], seropositivity for anti-HEV IgG among slaughterhouse workers in South Korea is relatively high. Furthermore, in our analyses, the seroprevalence of anti-HEV IgM might be underestimated, as we analyzed anti-HEV IgM only in anti-HEV lgG-positive samples. However, our study population is similar to those of a previous study in 2007, which, like the present study, comprised a majority of male subjects aged between 40 and 49 years [5]. This fact suggests that our study subjects are not selected by specific factors.

HEV seropositivity was not significantly different between slaughter workers and residual products handlers. However, there were significant differences in seropositivity according to sex and working duration. Differences due to sex in slaughter workers might be due to male, rather than female, workers being primarily in charge of physically demanding work. This work may in turn be associated with a lower likelihood of wearing PPE due to its burdensome nature. In addition, the risk of infection might increase for male workers, who are more likely to be in contact with blood or bodily secretions from livestock. In contrast, residual products handlers have fewer requirements for heavy physical work and this may explain why there was no difference in the seropositivity of antiHEV IgG by sex in this group of workers.

In South Korea, research focusing on zoonoses in high-risk groups is increasing, but there are few investigations into HEV. The present study is significant in that it provides an investigative survey of a high-risk group for zoonotic HEV, which is rare in the general Korean population.

In developed countries, HEV is known to be associated with domestic animals such as livestock, as well as with raw meat and pork products, and so it is more closely monitored [18-20]. Generally, North America and Europe are regarded as non-endemic areas of HEV infection, as the HEV seropositivity range is typically $1 \%$ to $5 \%$ [21]. However, even in non-endemic areas, some animals, such as swine, are known to be carriers of HEV [22]. Samples from two-month old pigs have shown positive test results for HEV RNA in Japan (2.7\%), Korea (1.6\%), and Taiwan (4.5\%), as have samples from slaughtered pigs in Canada (32.6\%) [23-26]. Among the main dairy production countries of Europe, seropositivity for anti-HEV IgG has been confirmed in pigs from Belgium (6.1\% to $7.2 \%)$, France (31\% to $65 \%)$, Germany (49.8\%), Netherlands (68\%), and northern Italy (87\%) [27]. Regarding domestic Korean HEV infection, the seropositivity of anti-HEV IgG on Jeju Island was found to be $55 \%$ in swine, compared to the $15.0 \%$ to $40.7 \%$ seropositivity between 2003 and 2007 and the HEV RNA detected in 17.5\% of swine in 2008 [28-30].

Another study reported that anti-HEV IgG was detected in $100 \%$ of swine breeders and $55 \%$ of adult blood donors in some Chinese provinces [31]. In Taiwan, seropositivity for anti-HEV IgG was $8 \%$ in the general population, but $27 \%$ in people in contact with swine [31]. In the American state of North Carolina, pig farmers showed a high level of seropositivity for anti-HEV IgG (11.0\%), which was 4.5 times higher than among other workers (2.4\%) [22]. In the present study, the seropositivity for anti-HEV lgG was higher than in Taiwan and North Carolina but less than in Chinese provinces. 
Wearing PPE such as gloves and masks is important in the prevention of zoonotic infection [32]. Among the work-related risk factors investigated in this study, the use of protective vinyl gloves, aprons, boots, and disposable protective suits was higher among slaughter workers with seropositivity for anti-HEV IgG compared to other workers. This suggests that a high usage of PPE does not prevent against zoonotic HEV infection, or that people identified as HEV seropositive may be more likely to wear PPE. It has previously been suggested that some operators may not be properly using PPE, or that PPE is ineffective [33]. Therefore, the correct use of PPE must be encouraged, and guidelines for usage may be necessary for workers. The discomfort and increased burden of wearing PPE (14.7\% in slaughter workers and $11.4 \%$ among residual product handlers) may contribute to the avoidance of this equipment, which may contribute to the difficulty in preventing zoonoses. Contact with livestock blood and bodily secretions more than once a week was more frequent among the slaughter workers testing negative for anti-HEV IgG compared to others; however, this association is inconsequential. Further study will assist in confirming the association of work-related risk factors with zoonotic infection. The association of some risk factors with HEV-lgG seropositivity may lead to controversial interpretation, highlighting the limitations of the cross-sectional nature of the present study. Subsequent case-control and cohort studies may be needed to address these limitations.

When investigating lifestyle-related risk factors, the proportion of slaughter workers who eat raw pork and beef was found to be significantly higher in the anti-HEV IgG seropositive group than in the control group. Since swine are an important vector for $\mathrm{HEV}$, public relations and education campaigns regarding the risks of HEV infection associated with consumption of raw pork and beef products need to be intensified. Given the recent increase in the number of restaurants, the frequency with which people may come into contact with zoonoses by ingesting meat products such as beef and pork, as well as potentially contaminated wild game, is greatly enhanced. In the stages of slaughter and processing of meat, workers come into contact with body tissue and fluids, increasing the likelihood of contamination with pathogens. HEV is primarily transmitted via the fecal-oral route [34]. At this stage, the surveillance and management of slaughterhouse workers is needed to limit contact with zoonoses. Further studies extending the present findings will confirm and improve the identification of work- and lifestyle-related risk factors for HEV infections associated with working in slaughter- houses. Future research will also facilitate the prevention of this infection in high-risk groups, such as slaughterhouse workers and administrative staff.

\section{ACKNOWLEDGEMENTS}

This study was supported by research grants from the KCDC in 2012 (no. 2012-E21004-00).

\section{CONFLICT OF INTEREST}

The authors have no conflicts of interest with the material presented in this paper.

\section{REFERENCES}

1. Taylor LH, Latham SM, Woolhouse ME. Risk factors for human disease emergence. Philos Trans R Soc Lond B Biol Sci 2001; 356(1411):983-989.

2. Lee K, Lim HS, Park WW, Kim SH, Lee DY, Park MY, et al. Seroprevalence of brucellosis among risk population in Gyeongsangbuk-do, 2006. J Prev Med Public Health 2007;40(4):285-290 (Korean).

3. Lee K, Lim HS. A study on the serologic responders to brucella antibody and those related risk factors among livestock workers in Korea. Dongguk J Med 2008;15(1):125-133 (Korean).

4. Choi KB, Lim HS, Lee K, Min YS. Awareness of major zoonoses among dairy farmers in Gyeonggi province. J Agric Med Community Health 2010;35(4):339-349 (Korean).

5. Yoo SJ, Choi YS, Lim HS, Lee K, Park MY, Chu C, et al. Seroprevalence and risk factors of brucellosis among slaughterhouse workers in Korea. J Prev Med Public Health 2009;42(4):237-242 (Korean).

6. Lim HS, Yoo SJ. Epidemiological characteristics of scrub typhus in Gyeongsangbuk-do, 2006. Dongguk J Med 2008;15(1):26-36 (Korean).

7. Lozano R, Naghavi M, Foreman K, Lim S, Shibuya K, Aboyans V, et al. Global and regional mortality from 235 causes of death for 20 age groups in 1990 and 2010: a systematic analysis for the Global Burden of Disease Study 2010. Lancet 2012;380 (9859):2095-2128.

8. Byun KS, Yeon JE, Kwon OS, Bak YT, Kim JH, Kwon SY, et al. Prevalences of IgG and IgM anti-HEV in patients with acute hepatitis of unknown causes and healthy adults in Korea. Korean J Gastroenterol 1996;28(5):661-668 (Korean). 
9. Ahn JM, Kang SG, Lee DY, Shin SJ, Yoo HS. Identification of novel human hepatitis $E$ virus (HEV) isolates and determination of the seroprevalence of HEV in Korea. J Clin Microbiol 2005;43(7):3042-3048.

10. Park HK, Jeong SH, Kim JW, Woo BH, Lee DH, Kim HY, et al. Seroprevalence of anti-hepatitis E virus (HEV) in a Korean population: comparison of two commercial anti-HEV assays. BMC Infect Dis 2012;12:142.

11. Yoon Y, Jeong HS, Yun H, Lee H, Hwang YS, Park B, et al. Hepatitis $E$ virus (HEV) seroprevalence in the general population of the Republic of Korea in 2007-2009: a nationwide cross-sectional study. BMC Infect Dis 2014;14:517.

12. Pérez-Gracia MT, García-Valdivia MS, Galán F, Rodríguez-Iglesias MA. Detection of hepatitis $E$ virus in patients sera in southern Spain. Acta Virol 2004;48(3):197-200.

13. Teo CG. Hepatitis E indigenous to economically developed countries: to what extent a zoonosis? Curr Opin Infect Dis 2006;19(5): 460-466.

14. Krumbholz A, Mohn U, Lange J, Motz M, Wenzel JJ, Jilg W, et al. Prevalence of hepatitis E virus-specific antibodies in humans with occupational exposure to pigs. Med Microbiol Immunol 2012;201(2):239-244.

15. Li TC, Chijiwa K, Sera N, Ishibashi T, Etoh Y, Shinohara Y, et al. Hepatitis $E$ virus transmission from wild boar meat. Emerg Infect Dis 2005;11(12):1958-1960.

16. Drobeniuc J, Favorov MO, Shapiro CN, Bell BP, Mast EE, Dadu A, et al. Hepatitis $E$ virus antibody prevalence among persons who work with swine. J Infect Dis 2001;184(12):1594-1597.

17. Boxall E, Herborn A, Kochethu G, Pratt G, Adams D, ljaz S, et al. Transfusion-transmitted hepatitis $\mathrm{E}$ in a 'nonhyperendemic' country. Transfus Med 2006;16(2):79-83.

18. Kamar N, Bendall R, Legrand-Abravanel F, Xia NS, ljaz S, Izopet J, et al. Hepatitis E. Lancet 2012;379(9835):2477-2488.

19. Maylin S, Stephan R, Molina JM, Peraldi MN, Scieux C, Nicand E, et al. Prevalence of antibodies and RNA genome of hepatitis $\mathrm{E}$ virus in a cohort of French immunocompromised. J Clin Virol 2012;53(4):346-349.

20. Clemente-Casares P, Pina S, Buti M, Jardi R, Martln M, Bofill-Mas $S$, et al. Hepatitis $E$ virus epidemiology in industrialized countries. Emerg Infect Dis 2003;9(4):448-454.

21. Paul DA, Knigge MF, Ritter A, Gutierrez R, Pilot-Matias T, Chau $\mathrm{KH}$, et al. Determination of hepatitis $\mathrm{E}$ virus seroprevalence by using recombinant fusion proteins and synthetic peptides. J Infect Dis 1994;169(4):801-806.

22. Meng XJ, Purcell RH, Halbur PG, Lehman JR, Webb DM, Tsare- va TS, et al. A novel virus in swine is closely related to the human hepatitis E virus. Proc Natl Acad Sci U S A 1997;94(18): 9860-9865.

23. Okamoto H, Takahashi M, Nishizawa T, Fukai K, Muramatsu U, Yoshikawa A. Analysis of the complete genome of indigenous swine hepatitis E virus isolated in Japan. Biochem Biophys Res Commun 2001;289(5):929-936.

24. Choi IS, Kwon HJ, Shin NR, Yoo HS. Identification of swine hepatitis $E$ virus (HEV) and prevalence of anti-HEV antibodies in swine and human populations in Korea. J Clin Microbiol 2003; 41(8):3602-3608.

25. Wu JC, Chen CM, Chiang TY, Tsai WH, Jeng WJ, Sheen IJ, et al. Spread of hepatitis E virus among different-aged pigs: two-year survey in Taiwan. J Med Virol 2002;66(4):488-492.

26. Leblanc D, Poitras E, Gagne MJ, Ward P, Houde A. Hepatitis E virus load in swine organs and tissues at slaughterhouse determined by real-time RT-PCR. Int J Food Microbiol 2010; 139(3):206-209.

27. Van Hoecke F, Van Maerken T, De Boulle M, Geerts A, Vlierberghe V, Colle I, et al. Hepatitis E seroprevalence in east and west Flanders, Belgium. Acta Gastroenterol Belg 2012;75(3): 322-324.

28. Choi $C$, Chae C. Localization of swine hepatitis $E$ virus in liver and extrahepatic tissues from naturally infected pigs by in situ hybridization. J Hepatol 2003;38(6):827-832.

29. Lee SH, Kang SC, Kim DY, Bae JH, Kim JH. Detection of swine hepatitis $\mathrm{E}$ virus in the porcine hepatic lesion in Jeju Island. J Vet Sci 2007;8(1):51-55.

30. Kim SE, Kim MY, Kim DG, Song YJ, Jeong HJ, Lee SW, et al. Determination of fecal shedding rates and genotypes of swine hepatitis E virus (HEV) in Korea. JVet Med Sci 2008;70(12):1367-1371.

31. Meng XJ, Dea S, Engle RE, Friendship R, Lyoo YS, Sirinarumitr T, et al. Prevalence of antibodies to the hepatitis $E$ virus in pigs from countries where hepatitis $E$ is common or is rare in the human population. J Med Virol 1999;59(3):297-302.

32. Lee MB, Greig JD. A review of gastrointestinal outbreaks in schools: effective infection control interventions. J Sch Health 2010;80(12):588-598.

33. Shin HW, Kim TH, Kim GH. A study on the survey of worker's satisfaction with safety gear in structural frame work. J Korea Inst Build Constr 2008;8(2):131-136 (Korean).

34. Balayan MS, Andjaparidze AG, Savinskaya SS, Ketiladze ES, Braginsky DM, Savinov AP, et al. Evidence for a virus in non- $A$, non- $B$ hepatitis transmitted via the fecal-oral route. Intervirology 1983;20(1):23-31. 